\title{
BLASTOCYST-ELICITED IMMUNITY: FAILURE TO DEMONSTRATE IMMUNOLOGICAL CHARACTERISTICS IN MICE
}

\author{
D. A. JAMES AND S. M. YOSHIDA \\ Department of Biology, University of Saskatchewan, \\ Saskatoon, Saskatchewan
}

(Received 31st May 1972, accepted 15th Fune 1972)

\begin{abstract}
Summary. Blastocyst-elicited immunity in mice was tested by adoptive transfer, cytotoxic assay and incubation of blastocysts in vitro with serum and lymphocytes from primary blastocyst recipients. These tests suggest that blastocyst-elicited immunity may not be an immunological phenomenon.
\end{abstract}

Mouse blastocysts can develop in a variety of extrauterine situations. Such development can be inhibited by immunological means either by preimmunizing the host against transplantation antigens of the donor strain (Kirby, Billington \& James, 1966) or by incubating the blastocyst in vitro with serum or lymphocytes from similarly immunized mice (Heyner, Brinster \& Palm, 1969; James, 1969). This evidence implies that mouse blastocysts display transplantation antigenicity. Kirby (1968) has shown that a progressive inhibition of blastocyst development in ectopic sites can be obtained by repeated transfer of blastocysts to extrauterine sites in one host, thus implying that the blastocyst is immunogenic.

If the blastocyst is indeed immunogenic, specific immunity raised in a host by ectopically transplanted blastocysts should be transferrable to irradiated secondary hosts. Furthermore, serum and lymphoid cells from the primary host should exhibit immunological activity in vitro. The present experiments were designed to investigate some aspects of 'blastocyst-elicited immunity'.

The mice used were of the strains $\mathrm{C} 3 \mathrm{H} / \mathrm{HeJ}\left(\mathrm{H}-2^{\mathbf{k}}\right)$ and $\mathrm{C} 57 \mathrm{~B} 1 / 6 \mathrm{~J}\left(\mathrm{H}-2^{b}\right)$. Inbred blastocysts were flushed from the uterus of $\mathrm{C} 3 \mathrm{H}$ mice $3 \frac{1}{2}$ days post coitum and transferred to extrauterine sites in C57BL recipients. All recipients were males, between 10 and 16 weeks of age. Three groups of primary hosts were prepared as follows:

Group 1 C57BL ${ }_{0}^{\star}$, untreated.

Group 2 G57BL $\hat{\text {, }}$, having previously received four transplants, each of four C3H blastocysts, to the left testis (Day 1), left kidney (Day 15), right testis (Day 29) and left testis (Day 43).

Group 3 G57BL ${ }^{*}$, having previously received 6 weekly intraperitoneal injections of about $35 \times 10^{6} \mathrm{C} 3 \mathrm{H}$ spleen cells. 
Each group contained twelve mice. Ten days after the final treatment in each group, a test graft of one $\mathrm{C} 3 \mathrm{H}$ blastocyst was made to the right kidney of each primary host. The recipients were killed 10 days after receiving the test graft. At autopsy, serum and lymphoid cells were collected for subsequent tests and the right kidney was inspected to assess the growth of the test graft. The right kidney was removed, fixed in Bouin's fluid for $6 \mathrm{hr}$ and stored in $70 \%$ ethanol. The kidneys with test grafts were subsequently processed for histological examination of haemorrhage volume and counts of trophoblast nuclei (James \& Yoshida, 1972).

Secondary hosts for adoptive immunization were G57BL males, between 10 and 16 weeks of age, which had received a total body irradiation of $500 \mathrm{rad}$, $24 \mathrm{hr}$ before cell transfer. Irradiation factors were: $200 \mathrm{kV}, 15 \mathrm{~mA}, 0 \cdot 2 \mathrm{~mm} \mathrm{Sn}$ filter, HVL $1.27 \mathrm{~mm} \mathrm{A1}$, TSD $30 \mathrm{~cm}$, dose rate $26 \mathrm{rad} / \mathrm{min}$. Primary host lymphoid cells were obtained from spleen and lymph nodes and were washed and suspended in TG 199. Each secondary host received about $400 \times 10^{6}$ lymphoid cells by intraperitoneal injection. Three days after adoptive transfer, the secondary host received a test graft of one $\mathrm{C} 3 \mathrm{H}$ blastocyst to the right kidney. The secondary hosts were killed 10 days after grafting and the right kidney was inspected to assess the growth of the test graft. The right kidney was removed and processed for histological examination, as described for the primary hosts.

Serum from the primary hosts was tested for cytotoxic activity. After inactivation at $56^{\circ} \mathrm{C}$ for $30 \mathrm{~min}$, the serum was mixed with standard guinea-pig serum (Difco) and used in dilutions with TC 199 to incubate normal C3H lymphocytes as target cells. The cells were incubated at $37^{\circ} \mathrm{C}$ for $60 \mathrm{~min}$ and subsequently examined under phase contrast to determine the titre which would cause $50 \%$ cell death.

Serum and lymphocytes from primary hosts were also tested in vitro with zona-free $\mathrm{C} 3 \mathrm{H}$ blastocysts. The zona pellucida was removed using a $0.1 \%$ solution of pronase (Calbiochem, B grade) in phosphate-buffered saline and polyvinylpyrrolidone $(10 \mathrm{mg} / \mathrm{ml}$ ) (Bronson \& McLaren, 1970). The blastocysts were washed with TC 199 and incubated with serum and lymphocytes at $37^{\circ} \mathrm{C}$ for $18 \mathrm{hr}$. Following incubation, the blastocysts were transplanted to the right kidney of untreated C57BL male recipients to test viability and growth (James, 1969). These recipients were killed after 10 days and the right kidney was inspected.

Among the primary hosts, Groups 2 and 3 showed an effect on the blastocyst test graft. The test graft in Group-2 and -3 recipients gave rise to very small haemorrhagic nodules. Histological examination revealed a marked reduction in the number of trophoblast nuclei and in haemorrhage volume. Group-1 animals showed a normal gross haemorrhagic nodule. The difference was significant $(P<0.01)$. This confirmed earlier reports that immunological factors can inhibit blastocyst growth in ectopic sites (Kirby et al., 1966; Kirby, 1968; James \& Yoshida, 1972). In subsequent tests by adoptive transfer and in vitro, Group 3 differed significantly from Groups 1 and 2. In secondary hosts which had received lymphoid cells from Group-3 primary hosts, development of the test graft was inhibited. A haemorrhagic nodule was observed but it was much 
smaller than those in Groups 1 and 2. Histological examination revealed a significant reduction in trophoblast cell nuclei and haemorrhage volume $(P<0.05)$. There was no difference between Groups 1 and 2. Serum from Group-3 primary hosts exhibited a cytotoxic titre of $1 / 128$ to $1 / 256$. Serum from Groups 1 and 2 exhibited no cytotoxic activity. Zona-free $\mathrm{C} 3 \mathrm{H}$ blastocysts incubated in serum and cells from Group-3 animals showed inhibited development when they were subsequently transferred to the right kidney in untreated hosts. Serum and cells from Groups I and 2 did not appear to affect zona-free blastocysts at all.

From these results, it appears that immunity raised against transplantation antigens and demonstrable by cytotoxic assay, can prejudice blastocyst growth in primary hosts, be adoptively transferred to irradiated secondary hosts and can adversely affect blastocyst development in vitro. In comparison, "blastocystelicited immunity' can produce a progressive inhibition of blastocyst growth in the primary host, but no cytotoxic activity can be demonstrated in primary host serum. Furthermore, inhibition of blastocyst development cannot be adoptively transferred to irradiated secondary hosts and incubation of blastocysts with serum and cells from primary hosts does not appear to be detrimental to the blastocysts. These results suggest that blastocyst-elicited inhibition may not be an immunological phenomenon at all, or it may be such a weak immunological response that it cannot be demonstrated by the present test systems. If the blastocyst is immunogenic and elicits an immune response either against $\mathrm{H}-2$ antigens or against blastocyst-specific antigens (Heyner et al., 1969), such immunity should be transferable in vivo or demonstrable in vitro. If blastocystelicited inhibition is not an immunological phenomenon, we are left with the conclusion that it may be the manifestation of some other physiological response resulting from continued insult to the recipient.

This investigation was supported by Operating Grant A 5490 from the National Research Council of Canada.

\section{REFERENCES}

Bronson, R. A. \& McLaren, A. (1970) Transfer to the mouse oviduct of eggs with and without the zona pellucida. F. Reprod. Fert. 22, 129.

Heyner, S., Brinster, R. L. \& Palm, J. (1969) Effect of iso-antibody on pre-implantation mouse embryos. Nature, Lond. 222, 783.

James, D. A. (1969) Antigenicity of the mouse blastocyst masked by the zona-pellucida. Transplantation, 8, 846.

James, D. A. \& Yoshrda, S. M. (1972) Antigenicity of the mouse blastocyst. Can. F. Zool. (In press).

KIRBY, D. R. S. (1968) The immunological consequences of extra-uterine development of allogeneic mouse blastocysts. Transplantation, 6, 1005.

Kirby, D. R. S., Billington, W. D. \& James, D. A. (1966) Transplantation of eggs to the kidney and uterus of immunised mice. Transplantation, 4, 713. 